\title{
A qualitative investigation of barriers and facilitators of rehabilitation success from the psychosomatic inpatients' perspective
}

\author{
Anna Levke Brütt' \\ Julia Luise Magaard' \\ Sylke Andreas ${ }^{1,2}$ \\ Holger Schulz' \\ 'Department of Medical Psychology, \\ Center for Psychosocial Medicine, \\ University Medical Center Hamburg- \\ Eppendorf, Hamburg, Germany; \\ ${ }^{2}$ Psychology Institute, Alps-Adria- \\ University Klagenfurt, Klagenfurt, \\ Austria
}

This article was published in the following Dove Press journal:

Patient Preference and Adherence

19 September 2016

Number of times this article has been viewed

Objective: Psychosomatic inpatient rehabilitation aims at promoting functioning in patients with mental disorders. Although generally effective, some patients do not benefit from this rehabilitation and suffer from symptoms as well as functional impairment. This study aimed to identify patient-reported factors influencing activity and participation outcomes.

Subject and methods: Five focus groups with $\mathrm{N}=23$ former psychosomatic rehabilitation inpatients were conducted. The discussions focused on facilitators and barriers of treatment outcome. The material was analyzed inductively according to qualitative content analysis. Categories were derived from the material.

Results: Patients reported sociodemographic and clinical characteristics as well as personal factors, preparation before psychotherapy, and aspects of employment and health care as predictors of treatment success.

Conclusion: A wide range of possible factors that influence the course of functioning from the patients' perspective were determined. These factors can be assigned to the ICF conceptual model. Clinician and researcher perspectives may complement these factors.

Keywords: activities of daily living, qualitative study, psychiatric rehabilitation, patientcentered care

\section{Introduction}

Mental disorders are a key contributor to the global burden of disease and disability. ${ }^{1}$ People suffering from mental disorders experience impairments in their work, familial, and social environments. ${ }^{2}$ An assessment of health-related functioning is critical to understanding how an individual is impaired in daily life. ${ }^{3}$ The International Classification of Functioning, Disability, and Health (ICF) ${ }^{4}$ reflects this approach and supplements the International Classification of Diseases. ${ }^{5}$ The ICF consists of two parts: body functions and structures on the one hand and activity and participation on the other. Contextual factors are related to the physical, social, and attitudinal environment in which people live (environmental) as well as individual characteristics such as age, sex, social background, and lifestyle (personal). An individual's functioning and disability are influenced not only by the diagnosis of a mental disorder but also by contextual factors (see Figure 1). Therefore, the ICF integrates the biopsychosocial approach of disability and health and provides a framework that is applicable to mental disorders. ${ }^{6-9}$

The ICD diagnosis of a mental disorder can be supplemented by using the ICF. For example, a woman is diagnosed with recurrent major depressive disorder (health problem, F33.3, according to ICD-10 criteria). ${ }^{5}$ Her predominant symptoms include 


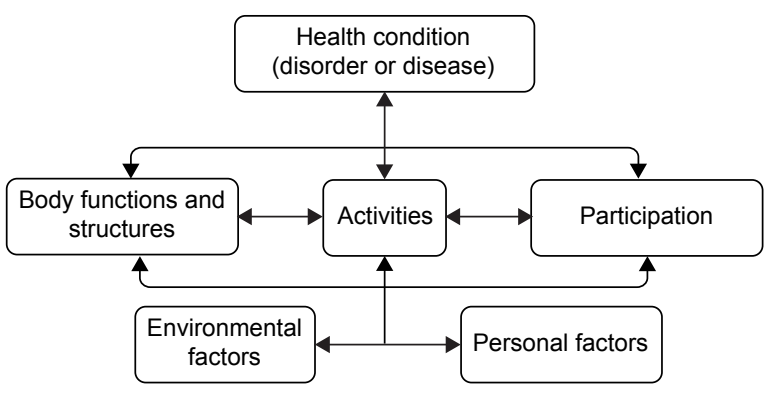

Figure I Components of the ICF.

Note: Reprinted from International Classification of Functioning, Disability and Health (ICF), World Health Organization. Copyright (200I). Available from: http:// www.who.int/classifications/icf/en/. Accessed August 2, $2016 .{ }^{4}$

Abbreviation: ICF, The International Classification of Functioning, Disability, and Health.

being in low mood and having sleep disturbances (body functions). It is hard for her to get up in the morning to take her children to school, and she very rarely meets friends (activities and participation). Her husband assists with household tasks (environmental factor). She accepts changing something to improve her well-being (personal factor). This description of her functioning and contextual factors provides significant information on her current needs and can be relevant for treatment planning.

Recent studies have shown the ICF is a useful framework and illustrates the importance of contextual factors for mental disorders: a review concluded that psychosocial difficulties in schizophrenia are closely related to environmental (eg, treatments received) and personal (eg, sociodemographic characteristics) factors. ${ }^{10}$ In patients with depression, perception and experience of social support, self-perception, self-efficacy, perception and experience of stigma, as well as coping strategies have been identified as relevant psychosocial difficulties. ${ }^{11}$ Personal and environmental factors are related to quality of life in patients with severe mental illness. ${ }^{12}$ A cross-sectional sample of patients with bipolar disorders, contextual factors including dysfunctional attitudes, and perceived social support could explain as much as $17.5 \%$ of patient functioning after controlling for sociodemographic and clinical factors. ${ }^{13}$

In Germany, the ICF is the conceptual framework for inpatient psychosomatic rehabilitation. ${ }^{14,15}$ Treatment targets the restoration and maintenance of psychosocial functioning, physical health, and participation in everyday aspects of life for patients with mental disorders. The effectiveness of psychosomatic rehabilitation treatment has been well examined, ${ }^{16,17}$ although some patients do not benefit from inpatient treatment. Several studies have investigated predictors for treatment success. ${ }^{18-21}$ In summary, it has been found that severity of the symptoms, number of sick days prior to inpatient treatment, and low treatment motivation are associated with low treatment success. ${ }^{18,21}$ In addition, patients with a secure attachment style benefit from psychosomatic treatment. ${ }^{21}$ Fliege et $\mathrm{al}^{20}$ reported that pessimism and selfefficacy significantly predict outcomes. Other demographic variables such as younger age, low education, and application for pension also affect treatment outcome. Nevertheless, in these studies, research on predictors has been limited to routinely assessed demographic and clinical characteristics and to treatment motivation. ${ }^{18,19,21}$ They have also focused on outcome expectancies or primarily disease-related variables, such as the duration of illness and the number of doctors consulted..$^{20}$ According to the biopsychosocial model and the ICF, however, environmental and personal factors should also be taken into account for predicting functioning.

The objective of this study was to broaden the range of potential risks and resources for a negative course of functioning identified in quantitative research with a qualitative and patient-centered approach. We asked patients about barriers and facilitators of the course of functioning after their psychosomatic inpatient rehabilitation treatment.

\section{Methods Design}

Because only limited knowledge about the influence of environmental and personal factors on functional outcomes exists, an exploratory approach was used. Face-to-face focus group discussions followed a structured outline. Trained researchers (JM [BA], NT [MA], ALB [PhD], all female) served as moderators, while patients served as experts. At the start, two moderators clarified the aims and expected benefits of this discussion. The relevance of the patients' experiences was accentuated. The discussions focused on facilitators and barriers for treatment success and were structured to identify factors before and during inpatient treatment as well as after discharge (see Table 1). The moderators allowed discussions between the participants and promoted them by asking deepening questions. Interviews were digitally recorded and transcribed. The focus group discussions lasted 115-135 minutes. The study was approved by the ethics committee of the Medical Association Hamburg. Patients gave written informed consent, and focus group statements were handled confidentially. Qualitative analysis was anonymized. The collected data are reported in such a way that persons could not be identified.

\section{Sampling}

We invited 365 former patients by mail. The former patients were involved in a prior study and had been treated in one 
Table I Interview guide for focus groups

\begin{tabular}{|c|c|c|c|}
\hline Part & Duration (min) & Content & Questions \\
\hline Welcome & 5 & Moderators introduce themselves & \\
\hline Introduction & 5 & $\begin{array}{l}\text { Description of the project explanation } \\
\text { of the procedure }\end{array}$ & \\
\hline $\begin{array}{l}\text { Content I: } \\
\text { pretreatment }\end{array}$ & 20 & $\begin{array}{l}\text { Discussion focusing on factors prior } \\
\text { to starting psychosomatic inpatient } \\
\text { treatment }\end{array}$ & $\begin{array}{l}\text { Before starting treatment, was there anything that helped } \\
\text { you participate in a more active life today? Before starting } \\
\text { treatment, was there anything that made it difficult for you to } \\
\text { participate in a more active life today? }\end{array}$ \\
\hline $\begin{array}{l}\text { Content II: } \\
\text { during treatment }\end{array}$ & 20 & $\begin{array}{l}\text { Discussion focusing on factors during } \\
\text { the course of psychosomatic inpatient } \\
\text { treatment }\end{array}$ & $\begin{array}{l}\text { Have you experienced something during treatment that } \\
\text { helped you participate in a more active life today? } \\
\text { Have you experienced something during treatment that made } \\
\text { it difficult for you to participate in a more active life today? }\end{array}$ \\
\hline Break & 10 & & \\
\hline $\begin{array}{l}\text { Content III: after } \\
\text { the treatment }\end{array}$ & 20 & $\begin{array}{l}\text { Discussion focusing on factors after } \\
\text { psychosomatic inpatient treatment }\end{array}$ & $\begin{array}{l}\text { After finalizing treatment, what has helped you to become } \\
\text { active again? After finalizing treatment, what has made it } \\
\text { difficult for you to become active? }\end{array}$ \\
\hline End & 15 & Summary of the discussion evaluation & \\
\hline
\end{tabular}

of two cooperating inpatient psychosomatic rehabilitation clinics 12-24 months prior. If the patients agreed to take part in the focus group interviews, they were contacted to arrange dates and accommodation if needed. The focus groups took place in the clinics in which the participants had been treated in previously. Travel costs could be reimbursed upon request. For all patients, data on the course of functioning during and after their inpatient treatment (pretreatment, posttreatment, and at 6 months follow-up) were available from the prior study. We received 35 replies from patients willing to take part in the study. Due to conflicting appointments, too many expenses and spontaneous cancellations, 13 patients did not participate in the focus groups. Finally, a sample of 23 patients participated in 5 focus group discussions 18-24 months after their inpatient stay. Each focus group consisted of 3-6 participants. According to our purposive sampling strategy, we predefined relevant characteristics of our sample: participants should vary in sex, age, and treatment outcome (Table 2). The recruited sample consisted of 16 women; 12 participants were younger than 50 years. The

Table 2 Distribution of course after discharge from inpatient treatment across age and sex of participants

\begin{tabular}{|c|c|c|c|}
\hline Course of rehabilitation & I 8-49 years & $50-65$ years & Overall \\
\hline \multicolumn{4}{|l|}{ Favorable course } \\
\hline q & 5 & 0 & 5 \\
\hline$\hat{0}$ & 0 & 3 & 3 \\
\hline \multicolumn{4}{|l|}{ Unchanged course } \\
\hline q & 5 & 3 & 8 \\
\hline 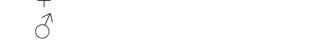 & I & 1 & 2 \\
\hline \multicolumn{4}{|l|}{ Unfavorable course } \\
\hline$q$ & 0 & 2 & 2 \\
\hline o & I & 0 & I \\
\hline Overall & 12 & 9 & $21^{a}$ \\
\hline
\end{tabular}

Note: a Course data for two participants is missing. $q$, female; $\partial$, male. reliable change index $(\mathrm{RCI})^{22}$ was used to classify ICF-A\&P results of the patients according to their treatment course. Most patients participating in the focus groups had a favorable or unchanged course; additionally, three patients with unfavorable functioning participated (Table 2). The majority of participants $(n=14)$ had been diagnosed with an affective disorder in the course of psychosomatic rehabilitation. Three participants received a diagnosis of personality disorder, and another two participants received diagnoses of adjustment disorders. The diagnoses of the four remaining participants were eating disorder, dissociative disorder, anxiety, and somatoform disorder.

\section{Analysis}

The material was analyzed inductively according to qualitative content analysis. ${ }^{23}$ Categories were derived inductively from the material without formulating concepts in advance. According to the process model of Mayring, ${ }^{23}$ we first defined the aim of the analysis. The objective was to identify barriers and facilitators influencing activity and participation outcomes after inpatient psychotherapy. A researcher (ALB) read the transcripts of two focus groups and generated categories. Afterward, we (ALB, JM, HS) checked the categories and the fit between categories and objective of the analysis once again. Finally, we went through the whole material. The result of this analysis was an elaborate category system. All steps of the analysis were performed using the computer software MAXqda (VERBI GmbH, Berlin, Germany). ${ }^{24}$

\section{Results}

The following six main categories emerged from the patients' statements: social environment, the person (person's 
resources and dealing with mental illness), preparation for the hospital stay, aspects of work and health care, as well as clinical characteristics. Each main category comprised a number of subcategories. Figure 2 illustrates the categories and subcategories in detail.

\section{Social environment}

The category social environment corresponds to relationships and contact with family and friends. Various aspects of social environment were particularly salient in the discussions. Respondents appreciated the understanding of their special situation and support in all these relationships. The analysis showed that sustainable family structures were identified as an important positive factor after discharge. Respondents referred particularly to "family strains" as barriers to treatment success after discharge. Some respondents emphasized that situations in the family that put a strain on the patient, such as responsibilities at home, were difficult for them. Having a circle of friends and a solid relationship was considered as a supportive factor in a number of respondents. One respondent commented that "having no problems in my relationship was supportive".

\section{Personal characteristics}

The category personal characteristics contained subcategories that refer to the person's resources, such as self-reflection, interpersonal skills and awareness and acceptance of personal limitations. Some respondents indicated that self-reflection, including health promotion and stress management, facilitated treatment success. For example, one respondent mentioned the concept of "mindfulness". Interpersonal skills such as openness were often emphasized. A respondent reported the following: "I have to say, that I do not have any problems speaking to strangers anymore". It was reported that being "unable to perceive [own] personal limitations" exacerbates the treatment success. Accordingly, awareness of personal limitations emerged as an important factor after discharge. In addition, some respondents stated that acceptance of personal limitations was very important and hard to achieve. Additionally, the subcategory acceptance of personal limitations also includes statements concerning the acceptance of a reduced level of functioning.

The category personal characteristics also contained subcategories that refer to mental illness directly: dealing with mental illness and (self)-stigmatization. The analysis showed that dealing openly with their mental illness was perceived as positive. For example, a respondent expressed the following: "I do not hesitate to say that I am mentally ill". Even aspects of self-stigmatization were mentioned, such as "I always feel guilty because I am unable to perform and work in a normal way".

\section{Preparation for inpatient care}

The category preparation for the hospital stay included the subcategories conscious decision for inpatient care, therapeutic experience, expectations as well as selection of clinic. Respondents emphasized that the ability to make a conscious decision for inpatient care was supportive for treatment success. Aspects of psychosomatic knowledge before hospital stay were described by many of the respondents as being related to a conscious decision for inpatient care. The respondents evaluated being persuaded of psychosomatic concepts at the beginning of the hospital stay as particularly helpful for facilitation of treatment success. Additionally, prior therapeutic experiences were regarded as helpful. In retrospect, the respondents concluded that certain expectations facilitated treatment success. The analysis showed that openness to the treatment as well as the desire to discover the reasons of their mental illnesses were especially important. The opportunity to choose their favored clinic was valued by consumers. The subcategory selection of clinic also refers to aspects of searching for suitable clinics. A respondent reported "I searched via the internet to find out which clinics are around and which ones I might consider".

\section{Work}

The category work comprised the following subcategories: working atmosphere, support at work, appropriateness of working conditions and professional perspective. Patients emphasized that having a "brilliant job" and "brilliant colleagues" who told them not to "stress [themselves]" and to communicate "if [they] have something on [their] mind[s]" was very supportive. Support during job reintegration was also experienced as helpful. Appropriateness of working conditions was considered as a relevant factor by a number of respondents. They indicated that the evaluation of the working conditions and whether the conditions met the personal needs of the patients was very important for them. The respondents often underlined the importance of their professional perspective after discharge. A respondent reported that "This [insecurity] is a factor which concerns my future and which leads to fluctuations of [my symptoms] at the moment". Another one mentioned "I think it helped me a lot - that my job was secure for the past two years".

\section{Health care}

The category health care comprised the subcategories trust in general practitioner, outpatient psychotherapy and differences between inpatient and outpatient experiences. The analysis of the responses suggested that trust in general practitioner was 

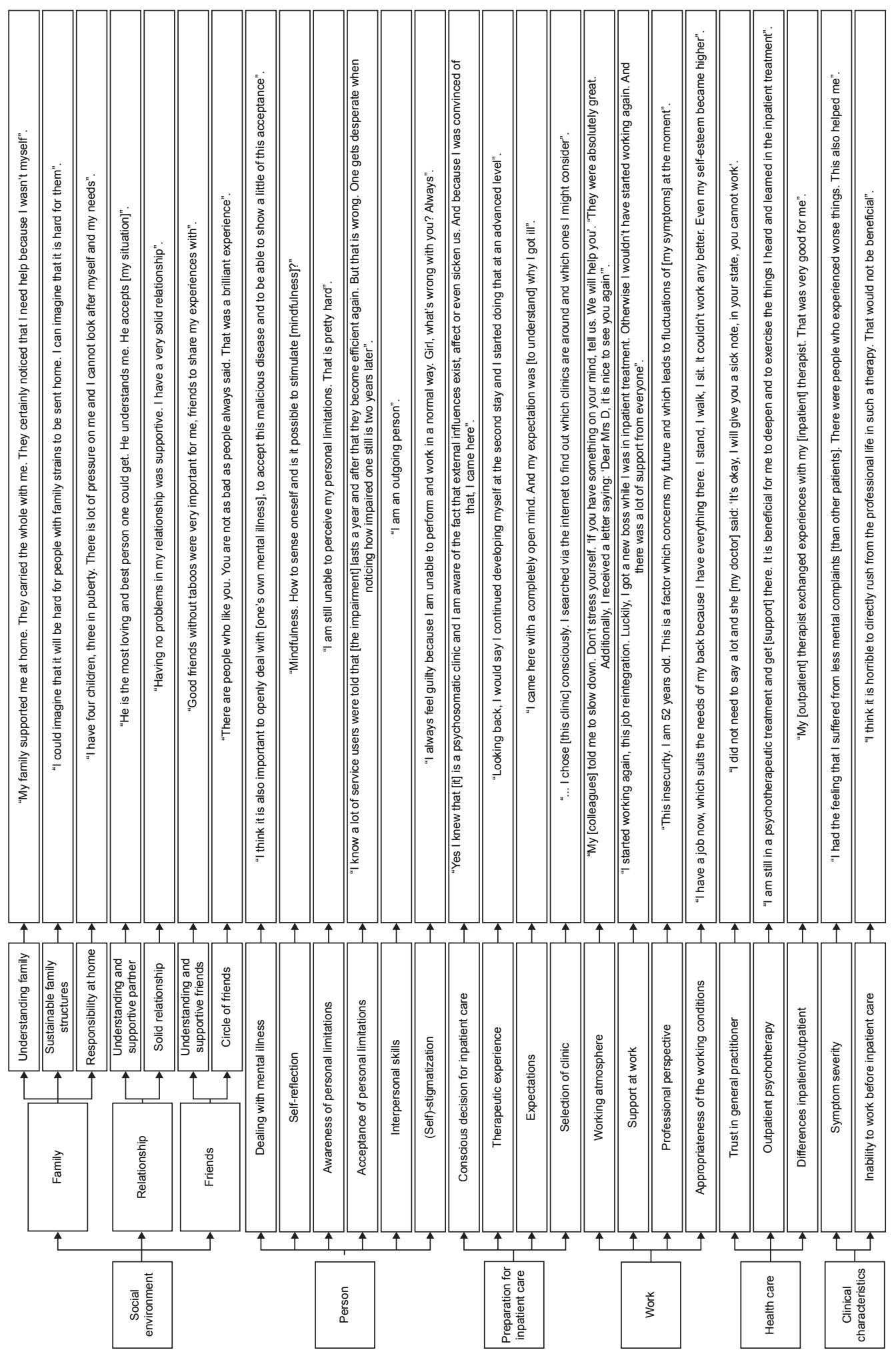

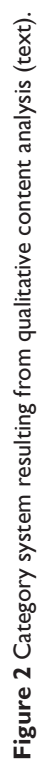


seen as very supportive. One respondent reported the following: "[my general practitioner] said 'You have to go and care for yourself. Do so and go there [to the clinic]'. She supported me a lot before and afterwards". Various aspects of outpatient psychotherapy after discharge were particularly salient in the discussions. Respondents appreciated having a place in an outpatient treatment program. Some respondents reported that it is very challenging to obtain a place. Lack of outpatient psychotherapy after discharge was considered as a risk factor in a number of respondents. The subcategory differences between inpatient and outpatient experiences focused on the question of transfer of inpatient into outpatient treatment and vice versa. Respondents reported on successful transfers of inpatient into outpatient treatment programs as well as problems with this process. Some respondents appreciated the exchange of experiences between the inpatient and outpatient therapists.

\section{Clinical characteristics}

The category clinical characteristics comprised the subcategories symptom severity and inability to work before inpatient care. Different levels of symptom severity were experienced as helpful at the beginning of the inpatient treatment: On one hand, noticing that one "suffer[s] from less mental complaints [than other patients]" was perceived as helpful by some respondents. On the other hand, it was reported that the relevant impairment, which includes exhaustion, was helpful for the effectiveness of the treatment. This is also reflected by the statement that inability to work before psychosomatic inpatient rehabilitation may be beneficial for the treatment process.

\section{Discussion}

Analyses of the group discussions with the patients show that personal characteristics and social environment are regarded as influencing the course after discharge from inpatient psychosomatic rehabilitation. These themes were complemented by aspects of employment, health care, inpatient stay preparation, and clinical characteristics.

Factors already identified through prior studies concerning predictors of treatment outcome ${ }^{18-21}$ may be supplemented by asking patients about barriers and facilitators of treatment success and psychosocial health. The collected data show the importance of social environment. The findings indicate that relationships to partners, family, and friends are relevant risks and resources in the social environment. From the patients' point of view, not only a lack of support in these relationships but also strains could constitute barriers for taking up and maintaining an active and participating lifestyle.
Further relevant findings are related to the person. These include preliminaries for psychosomatic inpatient rehabilitation, which subsumes aspects of treatment motivation, in addition to experiences with psychotherapy and expectations. In our study, the predictors self-efficacy and pessimism identified by Fliege et $\mathrm{al}^{20}$ are supplemented by further personal factors, such as self-reflection and openness as well as awareness and acceptance of personal limitations. Our findings suggest that dealing with mental illness and (self)stigmatization may also affect the course of activities and participation after inpatient psychosomatic rehabilitation.

Although experience with psychotherapy has so far not been evaluated as a predictor for psychosomatic rehabilitation, the data suggest that aspects of motivation such as the therapeutic experience and treatment expectations are of concern. Further research may be needed to evaluate whether therapeutic experience is an indicator for severity or whether realistic expectations, which may be manifested by experiences in therapeutic settings, positively influence treatment outcome.

Whereas previous research identified inability to work prior to inpatient treatment as a predictor of lower treatment success, ${ }^{19}$ our results suggest that other work-related factors, such as working atmosphere, support at work, appropriateness of working conditions, and professional perspective, may also influence outcomes. Furthermore, some patients in our study evaluated the inability to work before inpatient care as very beneficial for treatment success, whereas others stated that impairments may be a risk factor. Further research is needed to clarify the role of inability to work in this context.

It seems that with regard to health care, the confidence in outpatient health care, for example, in general practitioners and psychologists, is relevant. A special problem occurs when the inpatient setting and treatment is linked to outpatient mental health care. Problems may occur when there is no exchange between therapists, but also if treatment approaches are not compatible from the patient's point of view. Therefore, exchange between health care providers and treatment approaches may be a further environmental factor which has to be taken into account. Overall, from the patients' perspective, contextual factors appear to significantly influence activity limitations and participation restrictions after inpatient psychosomatic rehabilitation.

Limitations regarding the representativeness of the sampling must be considered. The response rate was quite low, and it is important to note that the respondents participated voluntarily and the statements might be influenced by 
self-selection. Through our purposive sampling strategy, we targeted the inclusion of heterogeneous rehabilitants. Nevertheless, we recruited only three patients with an unfavorable course, even though these patients may have deeper insights into barriers for recovery. Additionally, patients did not know the research group and the focus group moderators beforehand. A trustful environment is necessary to conduct focus groups. These may have turned out differently if prior therapists had acted as moderators. Nonetheless, the atmosphere was confidential, and the moderators saw patients as experts whose views provide important insights into the experience of barriers and facilitators. The neutral role of the moderators may also have facilitated the openness of the patients. In our qualitative analysis, the coding has been conducted by one of the authors (ALB) and was discussed in the authors' group.

Finally, the statements of the patients reflect their subjective perspective. The perspectives of relatives as well as therapists may complete the potential risks and resources.

Our study aimed at generating hypotheses. Further studies are needed to investigate whether the identified aspects empirically act as predictors for treatment outcome.

\section{Conclusion}

These results show that there might be many more factors that possibly influence the course of functioning and disability after discharge than what has come under investigation. Hence, our focus on contextual factors includes environmental and personal factors, as these can act as facilitators and barriers to functioning and health. These patient-specific set of contextual risk factors may also suggest a specific need for support. The need for treatment with a special focus on the promotion of activation and participation in daily life should be identified subsequent to or at the start of an inpatient psychosomatic treatment to attune the therapy to these specific needs.

\section{Acknowledgment}

The study was funded by the "Verein zur Förderung der Rehabilitationsforschung in Hamburg, MecklenburgVorpommern und Schleswig-Holstein (vffr)", an institution that supports rehabilitation research in the northern part of Germany.

We would like to thank Nora Tüpker (NT), who assisted in moderating two of the focus group discussions. Dr Silke Kleinschmidt and Dr Gabriele Fröhlich-Gildhoff facilitated this project in their psychosomatic inpatient clinics in Bad Malente and Bad Wildungen, Germany. Furthermore, we thank the 23 former patients who traveled up to $600 \mathrm{~km}$ to take part and offer their expertise in the focus group discussions.

\section{Disclosure}

The authors report no conflicts of interest in this work.

\section{References}

1. WHO. Global Burden of Disease: 2004 Update. Geneva, Switzerland: World Health Organisation; 2004

2. Wittchen HU, Jacobi F, Rehm J, et al. The size and burden of mental disorders and other disorders of the brain in Europe 2010. Eur Neuropsychopharmacol. 2011;21(9):655-679.

3. Salvador-Carulla L, Garcia-Gutierrez C. The WHO construct of health-related functioning $(\mathrm{HrF})$ and its implications for health policy. BMC Public Health. 2011;11(Suppl 4):S9.

4. WHO. ICF: International Classification of Functioning, Disability and Health. Geneva, Switzerland: World Health Organization; 2001. Available from: http://www.who.int/classifications/icf/en/. Accessed August 2, 2016.

5. WHO. International Statistical Classification of Diseases and Related Health Problems. 10th revision (ICD-10) ed. Geneva, Switzerland: World Health Organization; 1993.

6. Peterson DB. International classification of functioning, disability and health: an introduction for rehabilitation psychologists. Rehabil Psychol. 2005;50(2):105-112.

7. Baron S, Linden M. The role of the "International Classification of Functioning, Disability and Health, ICF" in the description and classification of mental disorders. Eur Arch Psychiatry Clin Neurosci. 2008; 258(Suppl 5):81-85

8. Reed GM, Spaulding WD, Bufka LF. The relevance of the International Classification of Functioning, Disability and Health (ICF) to mental disorders and their treatment. ALTER. 2009;3(4):340-359.

9. Kennedy C. Functioning and disability associated with mental disorders: the evolution since ICIDH. Disabil Rehabil. 2003;25(11-12): 611-619.

10. Switaj P, Anczewska M, Chrostek A, et al. Disability and schizophrenia: a systematic review of experienced psychosocial difficulties. BMC Psychiatry. 2012;12:193.

11. Kamenov K, Mellor-Marsá B, Leal I, Ayuso-Mateos JL, Cabello M. Analysing psychosocial difficulties in depression: a content comparison between systematic literature review and patient perspective. Biomed Res Int. 2014;2014:11.

12. Sanchez J, Rosenthal DA, Tansey TN, Frain MP, Bezyak JL. Predicting quality of life in adults with severe mental illness: extending the International Classification of Functioning, Disability, and Health Rehabil Psychol. 2016;61(1):19-31.

13. Sanchez-Moreno J, Martinez-Aran A, Gadelrab HF, et al. The role and impact of contextual factors on functioning in patients with bipolar disorder. Disabil Rehabil. 2010;32(Suppl 1):94-104.

14. Linden M. Psychosomatic inpatient rehabilitation: the German model. Psychother Psychosom. 2014;83(4):205-212.

15. Buschmann-Steinhage R, Brüggemann S. Changes in medical rehabilitation of the German Statutory Pension Insurance Scheme. Bundesgesundheitsblatt Gesundheitsforschung Gesundheitsschutz. 2011;54(4): 404-410. German.

16. Beutel ME, Bleichner F, von Heymann F, Tritt K, Hardt J. Inpatient psychosomatic treatment of anxiety disorders: comorbidities, predictors, and outcomes. Int J Clin Health Psychol. 2011;11(3):443-457.

17. Steffanowski A, Löschmann C, Schmidt J, Wittmann WW, Nübling R. Meta-analysis of the Effects of Inpatient Psychosomatic Rehabilitation. Bern, Switzerland: Huber; 2007. German.

18. Oster J, Muller G, Wietersheim J. "Who profits?" - patient characteristics as outcome predictors in psychosomatic rehabilitation. Rehabilitation. 2009;48(2):95-102. German. 
19. Lange M, Franke W, Petermann F. Who does't benefit from psychosomatic rehabilitation. Die Rehabilitation. 2012;51(6):392-397. German.

20. Fliege H, Rose M, Bronner E, Klapp BF. Predicting long-term outcome of in-patients psychosomatic treatment. Psychother Psychosom Med Psychol. 2002;52(2):47-55. German.

21. Herrmann AS, Huber D. The influence of patient- and treatment-related factors on the success of inpatient psychotherapy. Z Psychosom Med Psychother. 2013;59(3):273-289. German.
22. Jacobson NS, Truax P. Clinical significance: a statistical approach to defining meaningful change in psychotherapy research. $J$ Consult Clin Psychol. 1991;59(1):12-19.

23. Mayring P. Qualitative content analysis. Forum Qual Soc Res. 2000;1(2):Art. 20, http://nbn-resolving.de/urn:nbn:de:0114-fqs0002204

24. MAXQDA, software for qualitative data analysis [computer program]. Version 2. Berlin, Germany: VERBI Software-Consult-Sozialforschung $\mathrm{GmbH} ; 2001$.

\section{Publish your work in this journal}

Patient Preference and Adherence is an international, peer-reviewed, open access journal that focuses on the growing importance of patient preference and adherence throughout the therapeutic continuum. Patient satisfaction, acceptability, quality of life, compliance, persistence and their role in developing new therapeutic modalities and compounds to optimize clinical outcomes for existing disease states are major areas of interest for the journal. This journal has been accepted for indexing on PubMed Central. The manuscript management system is completely online and includes a very quick and fair peer-review system, which is all easy to use. Visit http://www. dovepress.com/testimonials.php to read real quotes from published authors.

Submit your manuscript here: http://www.dovepress.com/patient-preference-and-adherence-journal 